\title{
Anti-Inflammatory Effects of Tanshinone IIA on Atherosclerostic Vessels of Ovariectomized ApoE-/- Mice are Mediated by Estrogen Receptor Activation and Through the ERK Signaling Pathway
}

\author{
Xin Liu'a,b Chun-Yu Guo ${ }^{b} \quad$ Xiao-Juan Ma ${ }^{b}$ Cai-Feng Wu ${ }^{b} \quad$ Ying Zhang \\ Ming-Yue Sun ${ }^{a, b}$ Yu-Ting Panc Hui-Jun Yin ${ }^{a, b}$ \\ ${ }^{a}$ Academy of Chinese Medical Science, Beijing, ${ }^{b}$ Center of Cardiovascular Diseases, Xiyuan Hospital, \\ Beijing, 'Gansu University of Traditional Chinese Medicine, Gansu, China
}

\section{Key Words}

$17 \beta$-estradiol • Atherosclerosis • Anti-inflammation • ApoE-/- mice $\cdot$ ICI182780 • ERK1/2

\begin{abstract}
Aims: Estrogen plays a protective role in atherosclerosis. Our preliminary work demonstrated that the active conformation of Tanshinone IIA(TanIIA) is similar to the $17 \beta$-estradiol and it can bind to the estrogen receptor. Here, we hypothesized that Tanshinone IIA might have anti-inflammatory and anti-oxidative effects in atherosclerosis, mediated through estrogen receptor activation. Methods: Subjects for this study were $120 \mathrm{apoE}^{-/-}$female mice and 20 C57/ $\mathrm{BL}$ female mice. The apoE $\mathrm{E}^{-/-}$mice were ovariectomized (OVX) and the $\mathrm{C} 57 / \mathrm{BL}$ mice were sham ovariectomized. The sham OVX mice were maintained on a normal diet (NOR) group. The OVX apoE ${ }^{--}$mice were fed a high fat diet and randomly divided into 6 groups: Model (MOD) group which was fed a high fat diet only, $E_{2}$ group were given estrogen $\left(E_{2}\right) 0.13 \mathrm{mg} / \mathrm{kg} / \mathrm{d} ; E_{2}+I C I$ group were given $\mathrm{E}_{2}: 0.13 \mathrm{mg} / \mathrm{kg} / \mathrm{d}$ and ICI182780:65mg/ $\mathrm{kg} / \mathrm{m}$; TLD group (TanIIA low dose) were given TanIIA: $30 \mathrm{mg} / \mathrm{kg} / \mathrm{d}$; THD group (TanIIA high dose) were given TanIIA:60mg/kg/d; and TLD+ICI group were given TanIIA $30 \mathrm{mg} / \mathrm{kg} / \mathrm{d}$ and ICI $18278065 \mathrm{mg} / \mathrm{kg} / \mathrm{m}$. After three months of treatment, the aorta and the blood of the mice from each group was collected. The aorta were used for testing the lipid deposition by using hematoxylin and eosin(HE) and oil red $O$ staining and for testing the expression of $p$-ERK1/2 by Western blot. The blood was used for testing the serum cholesterol, superoxide dismutase (SOD), methane dicarboxylic aldehyde (MDA), nuclear factor kappa (NF-KB), soluble intercellular cell adhesion molecule-1 (sICAM-1), activating protein-1 (AP-1), E-selectin and 17ß-estradiol in serum. Results: Tanshinone IIA significantly reduced the lipid deposition in aorta, decreased the levels of total cholesterol (TC), triglyceride (TG), low density lipoprotein (LDL), very low density lipoprotein $(\mathrm{VLDL}), \mathrm{MDA}, \mathrm{NF}-\mathrm{KB}$, sICAM-1, AP-1, and E-selectin in serum but increased the levels of high density lipoprotein (HDL) and SOD in serum. Tanshinone IIA also suppressed the expression
\end{abstract}


of p-ERK1/2. Tanshinone IIA had no effect of level of serum $17 \beta$-estradiol levels. All of the effects of Tanshinone IIA were similar to estrogen and were inhibited by the estrogen receptor antagonist ICI182780. Conclusion: Tanshinone IIA may play an anti-inflammatory and antioxidative stress role in OVX atherosclerotic apoE $\mathrm{E}^{-/}$mice by activating the estrogen receptor through the ERK signaling pathway. Therefore, Tanshinone IIA, as a phytoestrogen, could be used for estrogen replacement therapy for cardiovascular disease of postmenopausal women.

Copyright $\odot 2015$ S. Karger AG, Basel

\section{Introduction}

The incidence of cardiovascular disease (CVD) in men is higher than women, but postmenopausal women have a higher risk of CVD with declining estrogen levels $[1,2]$. Thus, estrogen loss plays a key role in causing CVD in women. Estrogen replacement therapy (ERT) and hormone replacement therapy (HRT) are now important issues for cardiovascular health in women. Although it has been proved that estrogen plays an important role as an anti-inflammation [3-5], antioxidation [6-8] agent, in human vascular smooth muscle cells (VSMC) [9-11], ERT and HRT can also lead to a series of adverse side effects, such as venous thrombosis, stroke, as well as cancers of the breast, uterus and ovaries [12-15]. Thus, the use of estrogenic therapy for the prevention of cardiovascular disease is still in debate.

Atherosclerosis, the pathophysiological basis of coronary heart disease, is characterized by initial lipid deposition and an inflammatory response in the intima of blood vessels. Inflammation and oxidative stress play important roles in the progression of atherosclerosis and formation of vulnerable plaques [16-18].

Salvia miltiorrhiza is a Chinese herb reported to promote blood circulation and prevent blood stasis [19]. Tanshinone IIA(TanIIA), as the main lipophilic ingredient of Salvia miltiorrhiza, can significantly inhibit coronary artery contraction, improve coronary blood flow, exert anti-atherosclerotic actions, inhibit platelet aggregation and protect damaged endothelium [20-26]. Although there has been some research on the anti-inflammatory and anti-oxidative effects of TanIIA, these articles have not identificed a specific mechanism for these effects $[21,27]$. Our previous study found that TanIIA binds to the estrogen receptor with high affinity, and its active conformation is similar to $17 \beta$-estradiol ( $E_{2}$, Fig. 1). A phytoestrogen that has less adverse side effects could be an ideal agent for treating CVD in women. There are few studies of the estrogenic effect of the TanIIA [25]. We hypothesized that TanIIA has an estrogenic effect that protects against oxidative damage to endothelial cells; playing an anti-inflammatory and anti-oxidative stress role in atherosclerotic vessels by activating the estrogen receptor. We used an atherosclerotic animal model (ovariectomized female apoE ${ }^{-/}$mice fed a high fat diet) to verify (1) whether TanIIA can exert anti-inflammatory and anti-oxidative effects; (2) whether the mechanism of these effects is mediated by activating the estrogen receptor on the endothelial cells; and (3) via which signaling pathway TanIIA actives to produce its anti-inflammatory effects.

Fig. 1. Chemical structures of Tanshinone IIA and estradiol.

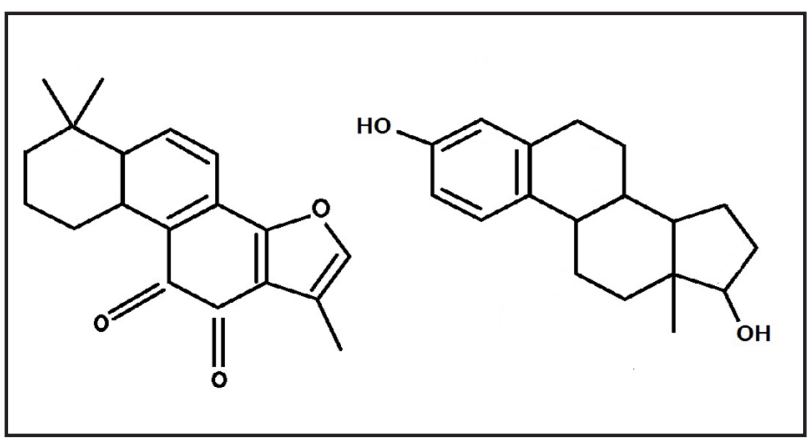




\section{Materials and Methods}

\section{Ethics statement, Chemicals and Reagents}

All animals experiments were permitted and approved by the Ethical Commission of Xiyuan Hospital (Beijing, China).

Normal and high fat feed(78.85\% normal feed, 21\% fat, $0.15 \%$ cholesterol) were purchased from Beijing HFK Bioscience Co., Ltd (Beijing, China). TanIIA was purchased from Xi'an HONSON Biotechnology Co., Ltd (Xi'an, China). Fulvestrant (ICI182780) was purchased from IPR Pharmaceuticals, INC. (Puerto Rico, USA). Estradiol valerate tablets $\left(\mathrm{E}_{2}\right)$ were purchased from Bayer Schering Pharma(Leverkusen, Germany). $\mathrm{E}_{2}$ and Tan IIA were dissolved in $0.5 \%$ sodium carboxymethylcellulose to make a mixed suspension.

\section{Low-estrogen atherosclerotic animal model}

Twenty C57/BL female mice weighing from 18 to $21 \mathrm{~g}$ (8 weeks old) were purchased from Vital River Laboratory Animal Technology Co. Ltd for the normal group (NOR:normal feed), and one hundred and twenty female apoE $/$ - mice weighing from 18 to $21 \mathrm{~g}$ (8 weeks old) were purchased from the same company and were randomly divided into 6 groups: model group (MOD: high fat feed), $17 \beta$-estrodial ( $\mathrm{E}_{2}$ :high fat feed and $\mathrm{E}_{2}: 0.13 \mathrm{mg} / \mathrm{kg} /$ day) group, $\mathrm{E}_{2}$ and ICI182780 ( $\mathrm{E}_{2}+\mathrm{ICI}:$ high fat feed; $\mathrm{E}_{2}: 0.13 \mathrm{mg} / \mathrm{kg} /$ day; ICI:65mg/ $\mathrm{kg} / \mathrm{month}$ ) group, low-dose TanIIA (TLD:high fat feed and TanIIA:30mg/kg/day) group, high-dose TanIIA(THD:high fat feed and TanIIA:60mg/kg/day) group, and low-dose TanIIA and ICI182780 (TLD+ICI:high fat feed; TLD:30mg/kg/day; ICI182780: 65mg/kg/month) group. And each group had 20 mice. All the apoE $/ \mathrm{mice}^{-}$ underwent sterile ovary ligation and ovariectomy, one week before oral administration of Tanshinone IIA and $\mathrm{E}_{2}$ and commencement of the high-fat diet. The C57/BL mice were given sham operation (needle threading, without ovary ligation and ovariectomy), and one week later were given oral administration of sodium carboxymethylcellulose vehicle and maintained on the normal diet. In addition, the mice in $\mathrm{E}_{2}+\mathrm{ICI}$ group and TLD+ICI group were given intramuscular injections of Fulvestrant (ICI182780) every month. After three months, the blood and aorta were collected for detection of treatment effects.

\section{Histopathological staining: Hematoxylin and eosin (HE) staining and Oil red $O$ staining}

To quantify the extent of atherosclerotic lesions, the aortic roots (from the aortic opening to $0.5 \mathrm{~cm}$ from the opening section of the aorta) were separated and stored in $4 \%$ paraformaldehyde for $\mathrm{HE}$ histopathological staining.

To test the lipid content in atherosclerotic blood vessels, the aortic roots (from aortic opening to $0.5 \mathrm{~cm}$ from the opening section of the aorta) were separated and stored in liquid nitrogen. Pre-frozen aortic roots were placed into molds with OCT compound and cut into $7 \mathrm{um}$ thick slices for oil red histopathological staining.

Measurement of serum blood fats, oxidative stress indicators, inflammatory factors and $E_{2}$ in mice

After maintenance on normal and high-fat diet for three months, each group of mice was fasted for 12 hours before the blood was collected. The serum was separated by centrifuge (3000rpm, 15min). The levels of serum TG (triglyceride), TC (total cholesterol), LDL (low density lipoprotein), VLDL (very low density lipoprotein) and HDL (high density lipoprotein) were quantified by biochemical analyzer. The levels of serum SOD (superoxide dismutase) and MDA (methane dicarboxylic aldehyde) were quantified by biochemical kit (NanJing JianCheng Bioengineering Institute, China). The levels of serum $\mathrm{E}_{2}$ (17 $\beta$-estradiol), NF- $\kappa B$ (nuclear factor kappa), AP-1 (activating protein-1), sICAM-1 (soluble intercellular cell adhesion molecule-1) and E-selectin were quantified by Elisa kit (cat: KGE014, 29516/10, 29517/10, DY796, DY575, R\&D Systems, USA).

\section{Western Blot analysis}

Mice aortas (from the opening of the aorta to the abdominal aortic bifurcation) were separated and washed twice with ice-cold PBS, then stored in liquid nitrogen. Aortas were ground into homogenates and lysed with SDS sample buffer (50mM Tris, pH8.0, $150 \mathrm{mM} \mathrm{NaCl}, 0.1 \% \mathrm{SDS})$. Equal amounts of protein $(40 \mu \mathrm{g})$ were resolved by SDS-PAGE (10\% standard gel) and transferred onto a nitrocellulose membrane (Millipore Corporation, Billerica, MA, USA). The membranes were blocked with Blocking solution (5\% non-fat milk TBST, TBST: $1 \times$ TBS add $1 \%$ Tween) at $37^{\circ} \mathrm{C}$ for 1 hour. The membranes were incubated with monoclonal 
primary antibodies against phospho-ERK1/2 (cat:4370s, Cell Signaling Technologies, USA) at 1:1000 dilution in blocking solution. After washing three times in TBST buffer, blots were incubated further with goat anti-rabbit horseradish peroxidase-conjugated secondary antibodies (cat:ZB-2301, ZSGB-BIO, Beijing, China) at a concentration of 1:2000 for $1 \mathrm{~h}$. The blots were then washed five times in TBST, and protein bands were detected by Enhanced Chemiluminescense (ECL, ThermoFisher, USA), and densitometric analyses were performed using IPP (Image-Pro Plus Analysis Soft ware, USA).

Statistical Analysis

All values are presented as mean \pm standard error of mean. The data were analyzed by one-way analysis of variance (ANOVA) followed by post hoc LSD t-test for multiple comparisons. Values of $\mathrm{P}<0.05$ or $\mathrm{P}<0.01$ were considered to be statistically significant.

\section{Results}

Apo: ${ }^{--}$mice have atherosclerosis after consuming a high-fat diet for three months

To identify whether the apoE $\mathrm{E}^{-/}$mice fed the high-fat diet had atherosclerosis, a crosssection of of the aorta was stained with HE. The vessel of C57/BL mice were chosen to be a control. The cross-section of C57/BL mouse aorta showed no atherosclerotic plaque. But the cross-section of the apoE $\mathrm{E}^{-/}$mouse aorta showed a large atherosclerotic plaque (Fig. 2).

TanIIA inhibits the lipid deposition in atherosclerotic vessels

To test the lipid content of atherosclerostic plaques in aortas of ovariectomized apo: $\mathrm{E}^{-}$ mice and the effects of TanIIA on the lipid deposition, aortic cross-section were stained with oil red 0 . The aortas of NOR group mice showed no red lipid deposition. The aortas of the $\mathrm{E}_{2}$ and THD groups also showed no obvious red lipid deposition. In contrast, the aortas of the apoE $\mathrm{E}^{-/}$mice in MOD, $\mathrm{E}_{2}+\mathrm{ICI}$, TLD and TLD+ICI group showed an obvious red color lipid deposition under the endothelial cells, which grew towards the inside of the vessel. Foam cells could also be found in the tunica intima, and there was loose gap between the tunica intima and the media smooth muscle cells (Fig. 3).

TanIIA decreases the levels of blood fats in ovariectomized apo $E^{-/}$mice

To test the levels of blood fats in ovariectomized apo: $\mathrm{E}^{-/}$mice and determine whether TanIIA can decrease the blood fats and improve the lipid metablism. After three months of high-fat diet and normal diet, all the mice were killed and blood was collected to measure circulating fat and cholesterol lipoproteins. The serum TG, TC, LDL and VLDL levels in MOD group were significantly higher than the NOR group, but the serum HDL level of MOD group was significantly lower than the NOR control. The serum TG, TC, LDL and VLDL levels in mice given oral administration of $\mathrm{E}_{2}$, TLD and THD group were significantly lower than the MOD group, but the serum HDL levels of $\mathrm{E}_{2}$, TLD and THD group were significantly higher than the MOD group. Mice treated with ICI182780 (the mice of $\mathrm{E}_{2}+$ ICI group had a higher levels of serum TG, TC, LDL and VLDL and lower level of serum HDL. But there is no difference between TLD group and TLD+ICI group (Table 1).

TanIIA increases serum SOD, and decreases serum MDA in ovariectomized atherosclerotic apoE ${ }^{-/}$mice

To determine if TanIIA has anti-oxidative stress effects, we tested the effect of TanIIA on the levels of serum SOD and MDA in ovariectomized atherosclerotic apoE $/ /$ mice. All the mice were killed and blood was collected after three months of high-fat diet(HFD) and normal diet. Compared to the NOR group, the MOD group had a lower level of serum SOD, but a higher level of serum MDA. $E_{2}$, TLD and THD increased the level of serum SOD and decreased the level of serum MDA in ovariectomized atherosclerotic apo: ${ }^{-/}$mice, These effects were blocked by the estradiol receptor antagonist ICI182780. The effect of the low dose TanIIA $(30 \mathrm{mg} / \mathrm{kg}$ ) was much better than the high dose TanIIA(60mg/kg) (Fig.4). 


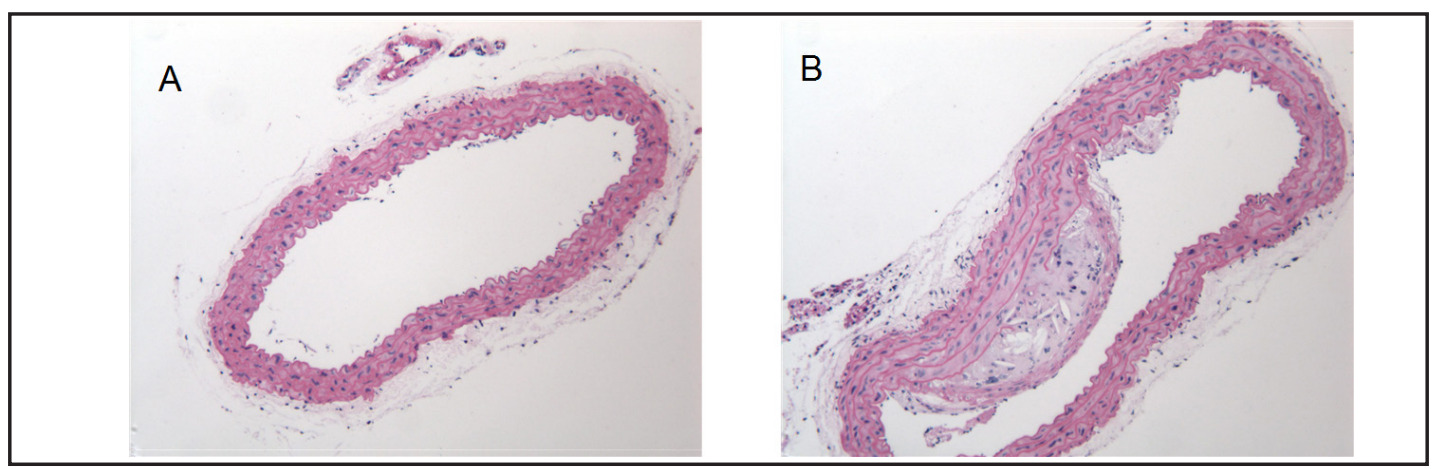

Fig. 2. HE staining (original magnification 100x). High-fat diet could aggravate the atherosclerosis of apoE $\%$ mice. (A) After three months of normal diet, C57/BL mice were killed and a cross-section of their aorta showed no atherosclerotic plaque. (B) After three month of high-fat diet, apoE $\mathrm{E}^{-/}$mice were killed and a cross-section of the aorta showed a large atherosclerotic plaque with loose fat cells under the fibrous cap.

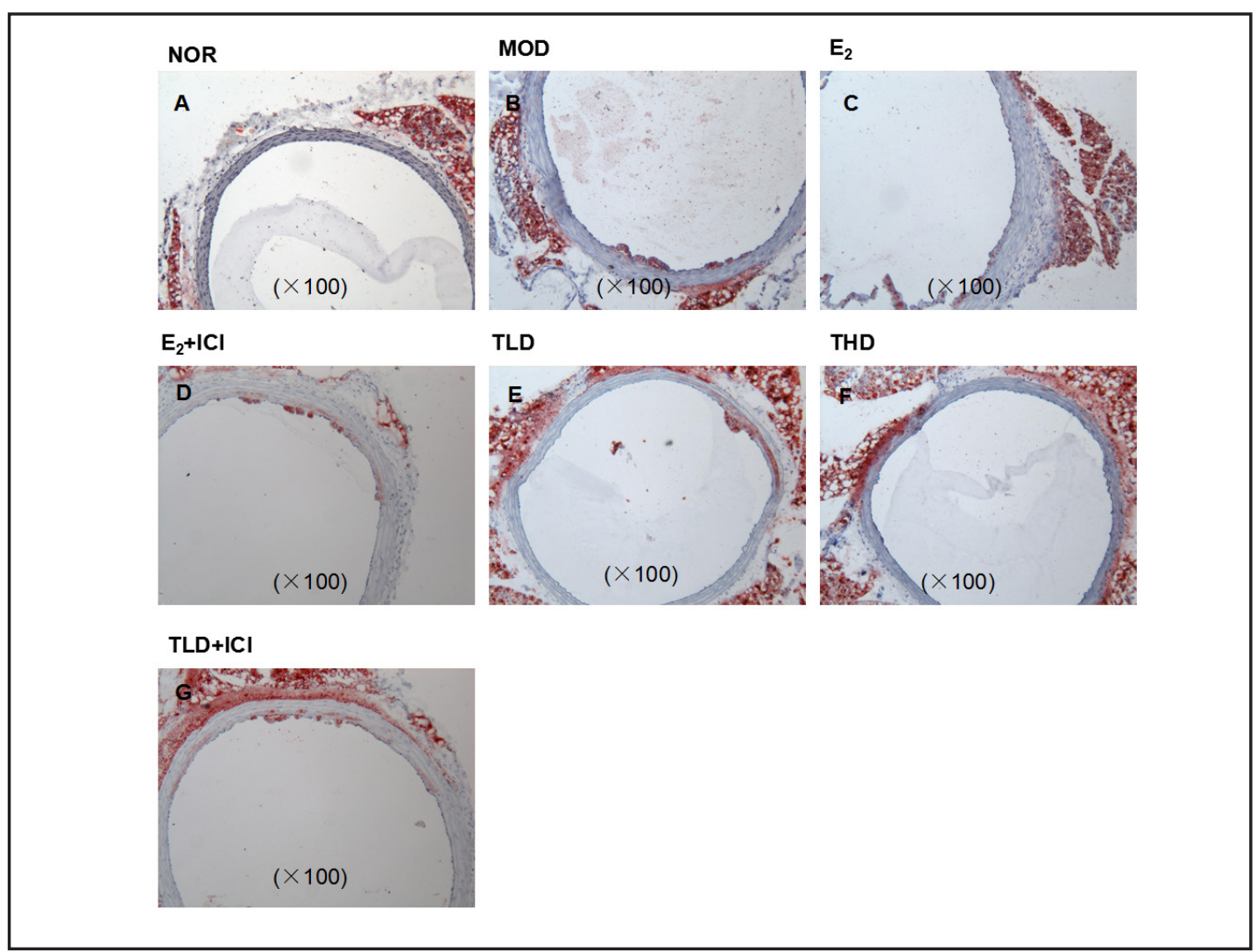

Fig. 3. Oil red 0 staining (original magnification 100x). High-fat diet could lead to the lipid deposition in aortas of ovariectomized apoE ${ }^{-/}$mice.(A) After three month of normal diet, C57/BL mice were killed. And the cross-section of normal aorta showed no red color lipid deposition. (B)(C)(D)(E)(F)(G)After three month of high-fat diet, apoE ${ }^{-/}$mice were killed. And the cross-section of the aorta showed an obvious red color lipid deposition.Foam cells can also be found in the tunica intima, and there was loose gap between the tunica intima and the media smooth muscle cells. (C)(F) $E_{2}$ and THD group had less red lipid deposition compared with other groups.

TanIIA has no significant effect on the serum $E_{2}$ levels in ovariectomized atherosclerotic apo $E^{-/}$mice

To determine whether TanIIA increases the serum $\mathrm{E}_{2}$ levels directly in ovariectomized atherosclerotic apo: $\mathrm{E}^{-/-}$mice and whether this effect is through estrogen receptor. After three KARGER 
Table 1. Effect of TanIIA on circulating fats and cholesterol lipoproteins in ovariectomized atherosclerotic apo $\mathrm{E}^{-/-}$mice. The mice were given oral administration of TanIIA and $\mathrm{E}_{2}$ every day, and intramuscular injection of ICI182780 every month. After three months of high-fat diet and normal diet, all the mice were killed, and blood was collected for the test of the blood fats. MOD group had a higher levels of TG, TC, LDL and VLDL and a lower level of HDL than NOR group. The $\mathrm{E}_{2}$, TLD, THD administered mice groups had lower levels of TG, TC, LDL and VLDL and a higher levels of HDL than the MOD group.ICI182780 inhibited the effects of $E_{2}$, but not TLD. ${ }^{*} P<0.05,{ }^{* *} P<0.01$ vs. NOR group; ${ }^{\Delta} P<0.05,{ }^{\triangle} P<0.01$ vs.MOD group; ${ }^{\wedge} P<0.05,{ }^{\Delta} \Delta P<0.01$ vs. $E_{2}$ group

\begin{tabular}{lllllll}
\hline Group & $\mathrm{N}$ & $\mathrm{TG}(\mathrm{mmol} / \mathrm{L})$ & $\mathrm{TC}(\mathrm{mmol} / \mathrm{L})$ & $\mathrm{HDL}(\mathrm{mmol} / \mathrm{L})$ & $\mathrm{LDL}(\mathrm{mmol} / \mathrm{L})$ & VLDL$(\mathrm{mmol} / \mathrm{L})$ \\
\hline NOR & 20 & $1.26 \pm 0.41$ & $2.08 \pm 0.20$ & $1.23 \pm 0.24$ & $0.35 \pm 0.11$ & $0.51 \pm 0.03$ \\
MOD & 20 & $1.43 \pm 0.39^{*}$ & $23.77 \pm 3.59^{* *}$ & $0.99 \pm 0.43^{*}$ & $4.83 \pm 1.01^{* *}$ & $17.96 \pm 2.92^{* *}$ \\
$\mathrm{E}_{2}$ & 20 & $1.15 \pm 0.34 \Delta$ & $16.73 \pm 3.36 \Delta$ & $2.21 \pm 0.28 \Delta \Delta$ & $4.04 \pm 0.63 \Delta$ & $11.99 \pm 2.67 \Delta \Delta$ \\
E $_{2}+\mathrm{ICI}$ & 20 & $1.40 \pm 0.08 \Delta$ & $22.27 \pm 2.09^{\Delta} \Delta$ & $1.19 \pm 0.29^{\Delta} \Delta$ & $4.66 \pm 0.34 \Delta$ & $16.03 \pm 1.70^{\Delta}$ \\
TLD & 20 & $1.09 \pm 0.13^{\Delta}$ & $15.85 \pm 4.27 \Delta \Delta$ & $1.50 \pm 0.24 \Delta$ & $3.71 \pm 0.80 \Delta \Delta$ & $11.64 \pm 3.37 \Delta \Delta$ \\
THD & 20 & $1.14 \pm 0.15 \Delta$ & $14.52 \pm 3.10 \Delta \Delta$ & $1.69 \pm 0.22 \Delta \Delta$ & $3.50 \pm 0.58 \Delta \Delta$ & $10.33 \pm 2.38 \Delta \Delta$ \\
TLD+ICI & 20 & $1.26 \pm 0.27 \Delta$ & $16.15 \pm 2.92 \Delta$ & $1.62 \pm 0.27 \Delta \Delta$ & $4.09 \pm 0.49 \Delta$ & $14.94 \pm 2.22^{\Delta}$ \\
\hline
\end{tabular}

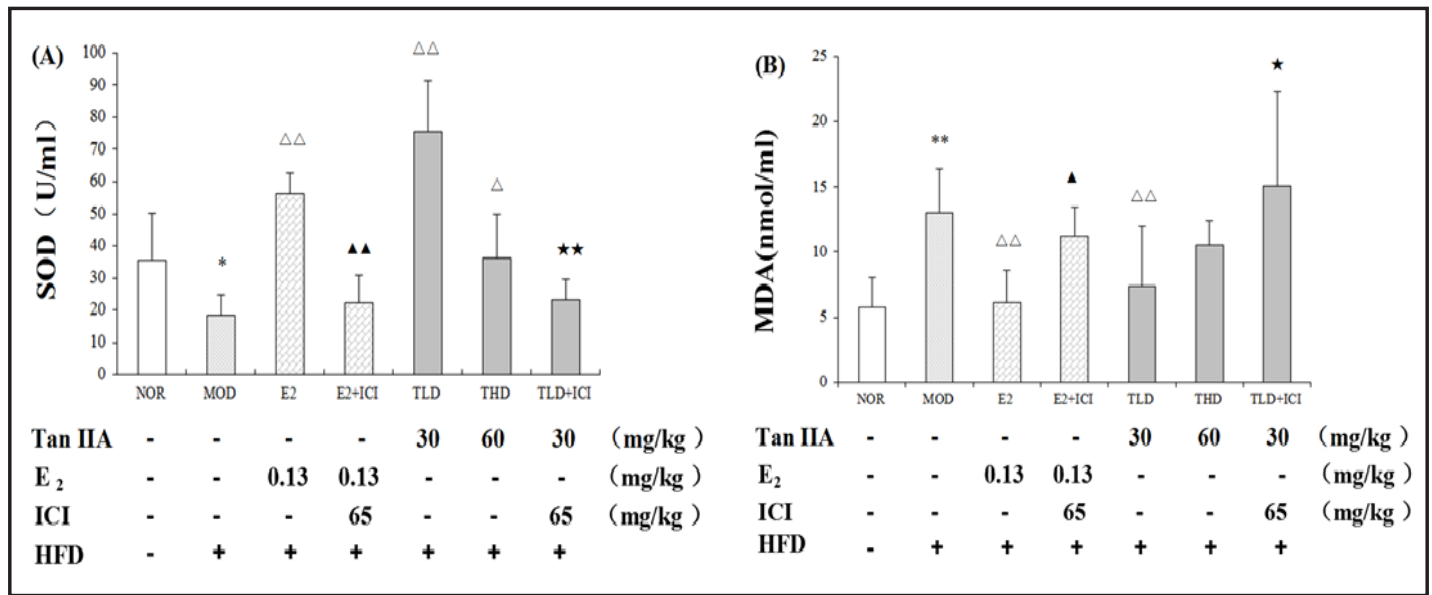

Fig. 4. Effect of TanIIA on serum SOD and MDA levels in ovariectomized atherosclerotic apoE ${ }^{-/}$mice.The mice were given oral administration of TanIIA and $E_{2}$ every day, and intramuscular injection of ICI182780 every month. After three months of high-fat diet(HFD) and normal diet, all the mice were killed, and blood was collected for the test of the serum SOD and MDA. The level of serum SOD in MOD group was lower than the NOR group, and the level of serum MDA in MOD group was higher than the NOR group. $\mathrm{E}_{2}$ and TanIIA increased the level of serum SOD, and decreased the level of serum MDA. The effect of $E_{2}$ and TanIIA were reversed by the ICI182780. Bars are displayed as mean \pm standard error of mean. ${ }^{*} P<0.05,{ }^{* *} P<0.01$ vs. NOR group; ${ }^{\wedge} P<0.05,{ }^{\triangle} P<0.01$ vs. MOD group; ${ }^{\wedge} P<0.05,{ }^{\wedge}{ }^{\wedge} P<0.01$ vs. $\mathrm{E}_{2}$ group; ${ }^{\star} P<0.05,{ }^{\star}{ }^{\star} P<0.01$ vs. TLD group.

months of high-fat diet and normal diet, all the mice were killed and blood was collected for the test of the serum $\mathrm{E}_{2}$. The serum $\mathrm{E}_{2}$ levels in MOD group were significantly lower than that of the NOR group. The serum $E_{2}$ levels in mice given oral administration of $E_{2}$ were higher than the MOD group, but TanIIA could not increase the level of $E_{2}$ in atherosclerotic apo $\mathrm{E}^{-}$ mice. The effects of TanIIA and $\mathrm{E}_{2}$ can not be inhibited by the ICI182780 (Fig. 5).

TanIIA decreases the levels of serum inflammatory factors in ovariectomized atherosclerotic apoE ${ }^{-/}$mice

After three months of high-fat diet and normal diet, all the mice were killed and blood was collected. The serum NF- $\mathrm{B}, \mathrm{AP}-1$, sICAM-1 and E-selectin levels in the MOD group were 
Fig. 5. Effect of TanIIA on serum $E_{2}$ level in ovariectomized atherosclerotic apoE $/$ mice.The mice were given oral administration of TanIIA and $\mathrm{E}_{2}$ every day, and intramuscular injection of ICI182780 every month. After three months of high-fat diet and normal diet, all the mice were killed, and blood was collected for the test of the serum $E_{2}$. The levels of serum $E_{2}$ in MOD group were lower than the NOR group. $\mathrm{E}_{2}$ increased the levels of serum $E_{2}$, but TanIIA had no effect on the levels of serum $E_{2}$ in atherosclerotic apo: ${ }^{-/}$mice. The effect was not reversed by the ICI182780. Bars are displayed as mean \pm standard error of mean. " $P<0.01$ vs.NOR group, ${ }^{\triangle} P<0.01$ vs. MOD group.
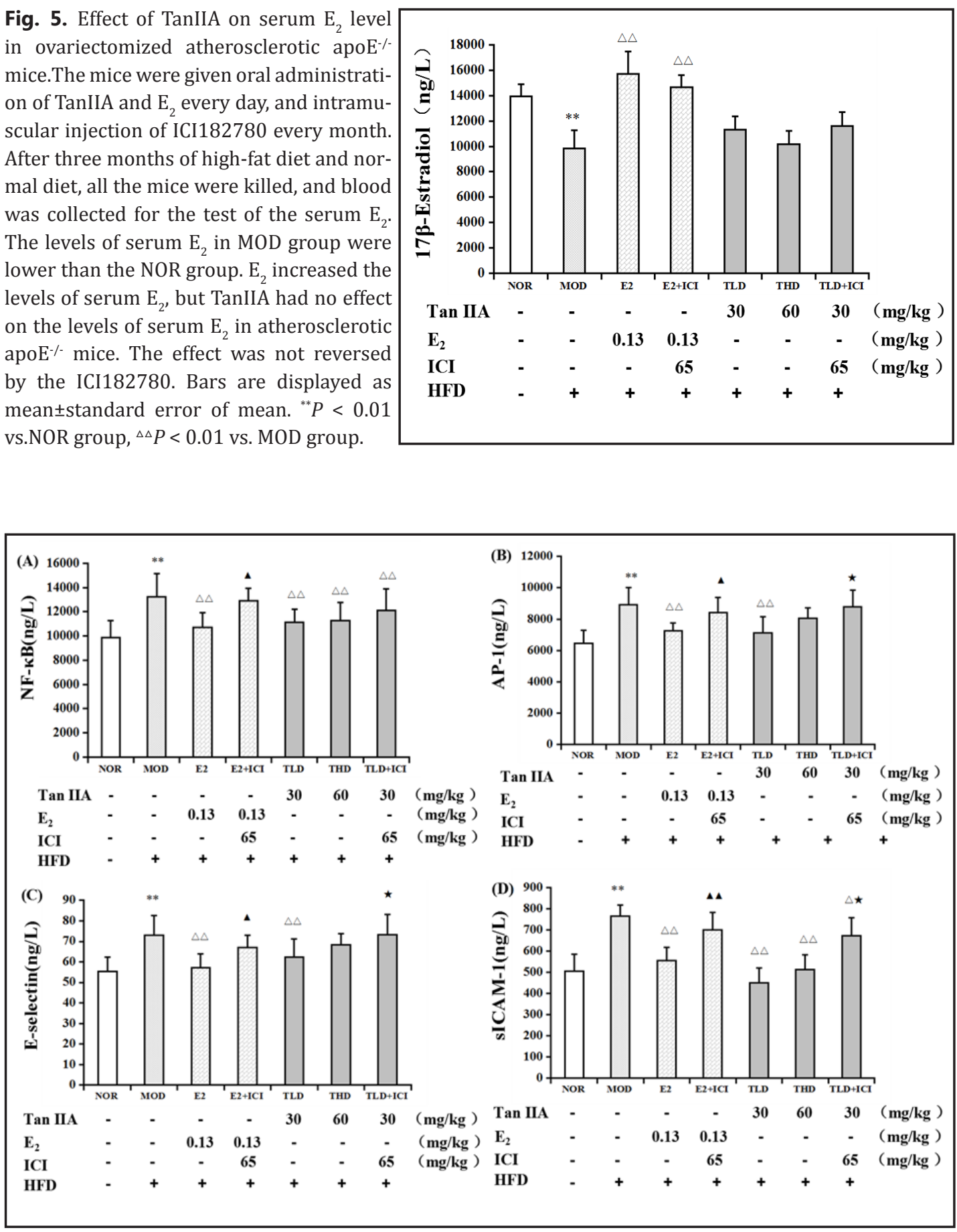

Fig. 6. Effect of TanIIA on the serum inflammatory factors levels in ovariectomized atherosclerotic apoE $/$ mice. The mice were given oral administration of TanIIA and $E_{2}$ every day, and intramuscular injection of ICI182780 every month. After three months of high-fat diet and normal diet, all the mice were killed, and blood was collected for the test of the serum NF- $\mathrm{KB}, \mathrm{AP}-1$, sICAM-1 and E-selectin. (A) TanIIA and $E_{2}$ inhibited the production of serum NF- $\kappa B$, and the effect was reversed by ICI182780. (B) TanIIA and $E_{2}$ inhibited the production of serum AP-1, and the effect was reversed by ICI182780. (C) TanIIA and $\mathrm{E}_{2}$ could inhibit the production of serum E-selectin, and the effect was reversed by the ICI182780.(D) TanIIA and $E_{2}$ inhibited the production of serum sICAM-1, and the effect was reversed by ICI182780. Bars are displayed as mean \pm standard error of mean. ${ }^{* *} P<0.01$ vs.NOR group, ${ }^{\Delta} P<0.05$ and ${ }^{\Delta} P<0.01$ vs.MOD group, ${ }^{\Delta} P<0.05$, $\triangle{ }^{\wedge} P<0.01$ vs. $\mathrm{E}_{2}$ group, ${ }^{\star} P<0.05$ vs. TLD group. 
Fig. 7. Effect of TanIIA on the expression of $\mathrm{p}$-ERK1/2 in aorta of ovariectomized atherosclerotic apoE ${ }^{-/}$mice. The mice were given oral administration of TanIIA and $\mathrm{E}_{2}$ everyday, and intramuscular injection of ICI182780 everymonth. After three month of high-fat diet and normal diet, all the mice were killed, and aortas were separated for Western Blot analysis. The expression of p-ERK1/2 were significantly increased in the atherosclerotic mice. TanIIA at $30 \mathrm{mg} / \mathrm{kg}$ and $60 \mathrm{mg} / \mathrm{kg}$ and $\mathrm{E}_{2}$ at $0.13 \mathrm{mg} / \mathrm{kg}$ could significantly inhibit the expression of p-ERK1/2 . And TanIIA at $30 \mathrm{mg} / \mathrm{kg}$ was more effective than TanIIA at $60 \mathrm{mg} / \mathrm{kg}$. The inhibition can be partly reversed by the ICI182780(65mg/kg). Bars are

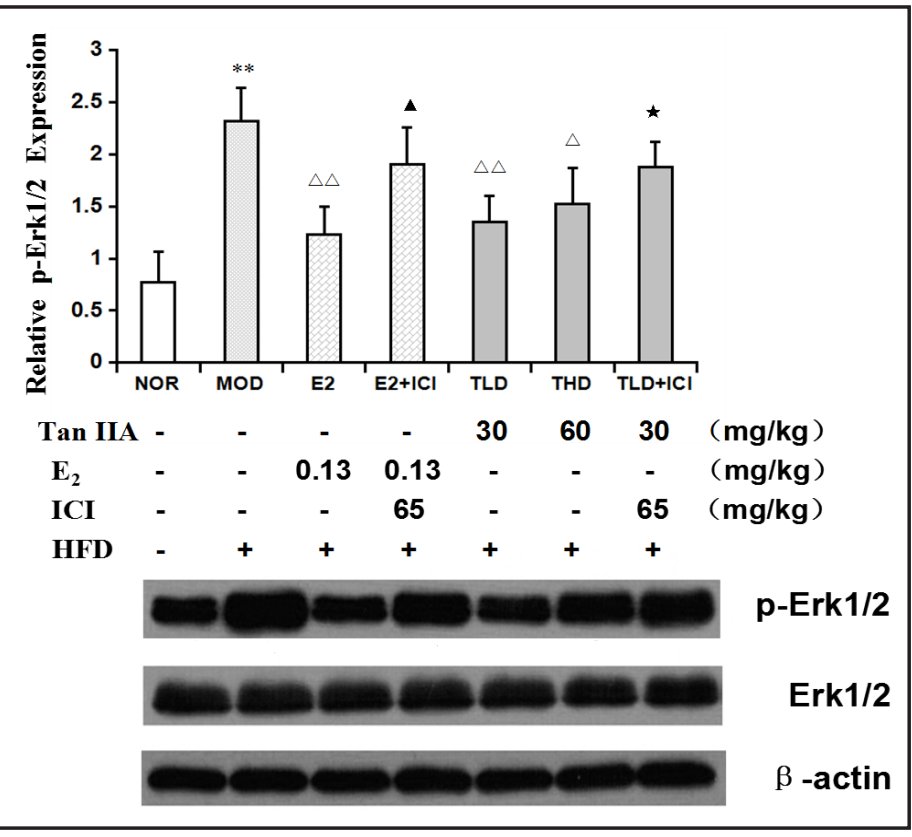
displayed as mean \pm standard error of mean. ${ }^{* *} P<0.01$ vs. NOR group, $\Delta P<0.05, \triangle \Delta P<0.01$ vs. MOD group, $\triangle P$ $<0.05$ vs. $\mathrm{E}_{2}$ group, ${ }^{\star} P<0.05$ vs. TLD group.

significantly higher than the NOR group. TanIIA and $\mathrm{E}_{2}$ significantly reduced the serum NF$\kappa \mathrm{B}, \mathrm{AP}-1$, sICAM-1 and E-selectin levels in atherosclerotic apoE $/-$ mice compared to the MOD group. The effect of the low dose TanIIA $(30 \mathrm{mg} / \mathrm{kg}$ ) was much better than the high dose TanIIA $(60 \mathrm{mg} / \mathrm{kg})$. The reduction of $\mathrm{E}_{2}$ and TanIIA can be partly reversed by the ICI182780 (Fig. 6).

TanIIA inhibits the expression of $p$-ERK1/2 in aorta of ovariectomized atherosclerotic apoE ${ }^{-1}$ mice.

After three months of high-fat diet, the apoE $\mathrm{E}^{-/-}$mice suffered from atherosclerosis. The aortas were dissected out for the Western Blot analysis. The expression of p-ERK1/2 was significantly increased in the atherosclerotic mice. TanIIA and $\mathrm{E}_{2}$ significantly inhibited the expression of p-ERK1/2. TanIIA at $30 \mathrm{mg} / \mathrm{kg}$ was more effective than TanIIA at $60 \mathrm{mg} / \mathrm{kg}$. The inhibition was reversed by the ICI182780 (Fig. 7).

\section{Discussion}

Our previous study showed that TanIIA has an estrogen-like structure which can bind to the estrogen receptor. We hypothesised that TanIIA may also play an estrogenic protective role on atherosclerosis.

In this study, we have demonstrated that (1) TanIIA can partly reduce lipid deposition under the endangium. (2) TanIIA reduces blood fats and cholesterol. (3) TanIIA decreases the inflammatory factors and oxidative-stress factors. And, (4) TanIIA can reduce the activation of ERK1/2 by decreasing formation of $\mathrm{p}$-Erk1/2 protein. All of these effects are similar to estrogen (17 beta-estradiol) and can partly be inhibited by the estrogen receptor antagonist ICI 182780. TanIIA itself did not increase the level of estrogen directly.

Estrogen can lower the lipid level in serum and lipid deposits in apoE ${ }^{-/-}$mice [28]. Estrogen reduces the plasma cholesterol in ovariectimized apo: $\mathrm{E}^{-/}$mice, and it is an estrogen receptor dependent process [29]. Tanshinone IIA has been shown to reduce the content of macrophages, cholesterol accumulation, and the development of atherosclerotic plaqued 
[30]. It also attenuates advanced atherosclerotic lesions in apoE-/- mice [21], but it does not alter serum lipid profile and body weight in apo $\mathrm{E}^{-/}$mice [21]. Our research supported the hypothesis that TanIIA can reduce undesirable lipid deposition. We found that TanIIA can decrease serum TG, TC, LDL and VLDL and increase the HDL level in ovariectimized apoE $\mathrm{E}^{-/}$mice, which is similar to the effect of estrogen administration, but this is not inhibited by ICI182780. For the apoE $\mathrm{E}^{-/}$mice, TanIIA did not decrease the serum lipid [21], but for the ovariectimized apo: $\mathrm{E}^{-/}$mice, supplementation of TanIIA could decrease the serum lipid, which strongly suggests that TanIIA has the estrogenic role.

Oxidative stress, which occurs in response to an altered metabolic state, and apoptosis and lipid peroxidation, is additionally involved in the pathogenesis of atherosclerosis [31]. SOD has been shown to be a potentially important mediator in the prevention of ox-LDL accumulation within atherosclerotic plaques [32]. MDA is a product of lipid peroxidation and we chose to test SOD and MDA to demonstrate the anti-oxidative stress effects of TanIIA. We found that after ovariectomy, and consumption of a high fat diet for three month, the mice had a higher level of MDA and a lower level of SOD compared to the NOR group. Supplementation of TanIIA reduced the level of MDA and increased the level of SOD in serum of mice, which is in accordance with previous studies on rabbits and rats [33, 34]. And the effect is similar to estrogen and can be blocked by estrogen receptor antagonists.

Inflammation plays an important role in the pathogenesis of vascular endothelial injury $[35,36]$. Endothelial dysfunction leads to atherosclerosis and restenosis by facilitating platelet adhesion and aggregation and by signaling the release of mitogens from platelets, macrophages, and endothelial cells, which stimulate smooth muscle cell proliferation [37]. Inflammatory markers, such as ICAM-1, VCAM-1, selectin, NF- $\kappa B$, TNF- $\alpha, \mathrm{AP}-1$, are important indicators of endothelial dysfunction [38]. It has been reported that TanIIA significantly reduces aortic expression of NF- $\kappa B$ and matrix metalloproteinase-9 (MMP-9) in apoE-/ mice [21]. This in vivo study was supported by our study demonstrating decreased serum levels of inflammatory indicators in ovariectomized apoE ${ }^{-/}$mice treated with TanIIA. In vitro studies provided corroborating evidence of an anti-inflammatory role of TanIIA. Ox-LDL(oxidized low density lipoprotein), TNF- $\alpha$ (Tumor Necrosis Factor), and LPS(lipopoly- saccharide) were given to the cells to make the injured endothelial model in vitro studies. TanIIA regulated TNF- $\alpha$-induced expression of VCAM-1 and ICAM-1 through inhibition of NF- $\mathrm{\kappa B}$ activation [39], suppressed oxidized LDL-induced pro-inflammatory cytokine (IL-1beta, IL-6, TNF- $\alpha$, MCP-1) expression [21, 25], and inhibited LPS-stimulated phosphorylation of NF- $\kappa$ Binducing kinase and IкB alpha kinase as well as the phosphorylation of p38, ERK1/2, and JNK [40], which supported the in vivo studies. Among them, one chain of research indicated that the anti-inflammatory effects of TanIIA are mediated by via ER-dependent pathways [25], but by which signal transduction pathway was not mentioned. Our study showed that Tan IIA is able to reduce serum levels of NF- $\mathrm{KB}, \mathrm{AP}-1$, sICAM-1, E-selectin in ovariectomized atherosclerotic apoE $\mathrm{E}^{-/}$mice. This suggests that estrogen plays a protective role for the vascular endothelial cells, which are estrogen receptor-independent and can be inhibited by the estrogen receptor antagonist ICI182780.

ERK, one of three well-characterized subfamilies of MAPK, phosphorylates specific tyrosine and threonine residues of target protein substrates, and regulates cellular activities that include gene expression, mitosis, movement, metabolism, survival, and programmed cell death [41-43]. The activation of the ERK signaling pathway is closely related to inflammation [44-47]. TanIIA has been reported to increase the level of NO and the expression of eNOS in cardiac microvascular endothelia by upregulating the expression of ERK1/2, which is similar to the estrogen and can be antagonized by estrogen receptor antagonist [48]. No information is available on the relationship among anti-inflammatory and anti-oxidant effects, estrogenic effects and signaling pathway. So, we tested the p-ERK1/2 expression in aorta of each group to see whether TanIIA and estrogen can reduce the secretion of inflammatory factors in mouse vessels and, is the mechanism caused by affecting the p-ERK1/2 protein in ERK signal passway? The results showed that the expression of p-ERK1/2 in the model group was higher than the normal control, which may illustrate that ERK1/2 is involved in the 
oxidative damage during the whole process of atherogenesis. TanIIA and estrogen reduced the expression of p-ERK1/2, and this effect was inhibited by an estrogen receptor antagonist. So we can conclude that TanIIA plays an estrogenic protective effect on vascular endothelial cells by downregulating the expression of p-ERK1/2.

We found that after removal of bilateral ovaries, the mice had a low serum estrogen levels, and the mice which were given oral estrogen had a high serum estrogen levels, but the mice which were given oral TanIIA had a low serum estrogen levels the same as the model group. Combinding the results, we inferred that TanIIA could be seen as a supplement of estradiol, and directly bind to the receptor.

We found that the effect of low dose of TanIIA is generally better than the high dose of TanIIA. We chose the $30 \mathrm{mg} / \mathrm{kg} / \mathrm{d}$ as the low dose, and the $60 \mathrm{mg} / \mathrm{kg} / \mathrm{d}$ as the high dose according to our previous research, which told us that there is a low absorbance rate of TanIIA in apoE $/$ mice. It seems that the estrogenic effect of TanIIA in low dose is better than that in high dose. And this results is opposite to other research which tells us that the effect of TanIIA in high dose is better than that in the low dose [49]. We should do further study about this.

We first used the ovariectimized apoE ${ }^{-/}$mice to establish the low-estrogen level atherosclerostic animal model, which may be similar to the postmenopausal atherosclerostic women. Our study was to investigate the anti-inflammatory and the anti-oxidative effect of TanIIA on ovariectimized atherosclerostic apoE $/$ mice, assuming that TanIIA has an estrogenic protective effect. Through experimental studies, it was confirmed that TanIIA can regulate the blood lipid level, inhibit lipid deposition and reduce the levels of inflammatory cytokines and the oxidative-stress factors by inhibiting the expression of downstream p-ERK1/2 protein of the ERK pathway, which is similar to estrogen and can be inhibited by an estrogen receptor antagonist. In the future, we will test the estrogenic effect of TanIIA in in vitro studies. Studies also need to be carried out to find out whether TanIIA has the adverse side-effect profile of estrogen. This study provided some experimental basis on the use of Salvia miltiorrhiza for the clinical treatment of postmenopausal women with CHD. TanIIA is, not just only an ingredient which can promote blood circulation and remove blood stasis in Salvia miltiorrhiza, but a phytoestrogen which can be used in estrogen replacement therapy.

\section{Acknowledgements}

We thank the financial support from National Natural Science Foundation of China (No. 81173584) and Beijing Natural Science Foundation (No.7122157).

\section{References}

1 American Heart Association: Heart and stroke statistical update, Dallas, Texas. AHA, 1999.

2 Mohle-Boetani J, Whittemore A: Menopause and the risk of coronary heart disease in women. N Engl J Med 1987;316:1105-1110.

3 Caulin-Glaser T, Farrell WJ, Pfau SE, Zaret B, Bunger K, Setaro JF, Brennan JJ, Bender JR, Cleman MW, Cabin HS, Remetz MS: Modulation of circulating cellular adhesion molecules in postmenopausal women with coronary artery disease. J Am Coll Cardiol 1998;31:1555-1560.

4 Koh KK, Bui MN, Mincemoyer R, Cannon RO 3rd: Effects of hormone therapy on inflammatory cell adhesion molecules in postmenopausal healthy women. Am J Cardiol 1997;80:1505-1507.

-5 Rodríguez E, López R, Paez A, Massó F, Montano LF 17Beta-estradiol inhibits the adhesion of leukocytes in TNF-alpha stimulated human endothelial cells by blocking IL-8 and MCP-1 secretion, but not its transcription. Life Sci 2002;71:2181-2193.

-6 Castanho VS, Nakamura RT, Pinto-Neto AM, Faria EC: Postmenopausal therapy reduces catalase activity and attenuates cardiovascular risk. Arq Bras Cardiol 2012;11,9:1008-1014. 


\section{Cellular Physiology Cell Physiol Biochem 2015;35:1744-1755

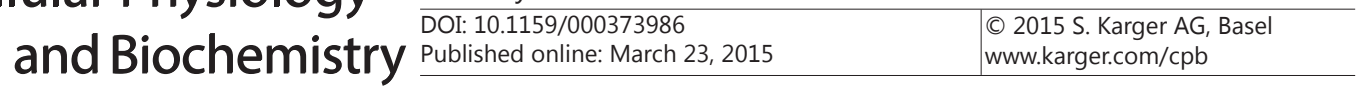

Liu et al: Estrogen-Like Anti-Inflammatory Effects of Tanshinone IIA

7 Haas MJ, Raheja P, Jaimungal S, Sheikh-Ali M, Mooradian AD. Estrogen-dependent inhibition of dextroseinduced endoplasmic reticulum stress and superoxide generation in endothelial cells. Free Radic Biol Med 2012;52:2161-2167.

8 Darabi M, Ani M, Movahedian A, Zarean E, Panjehpour M, Rabbani M: Effect of hormone replacement therapy on total serum anti-oxidant potential and oxidized LDL/ $\beta 2$-glycoprotein I complexes in postmenopausal women. Endocr J 2010;57:1029-1034.

-9 Li F, Yu X, Szynkarski CK, Meng C, Zhou B, Barhoumi R, White RE, Heaps CL, Stallone JN, Han G: Activation of GPER Induces Differentiation and Inhibition of Coronary Artery Smooth Muscle Cell Proliferation. PLoS One 2013;8:e64771.

10 Nakamura Y, Suzuki T, Miki Y, Tazawa C, Senzaki K, Moriya T, Saito H, Ishibashi T, Takahashi S, Yamada S, Sasano H: Estrogen receptors in atherosclerotic human aorta: inhibition of human vascular smooth muscle cell proliferation by estrogens. Mol Cell Endocrinol 2004;219:17-26.

- 11 Ueda K, Lu Q Baur W, Aronovitz MJ, Karas RH: Rapid estrogen receptor signaling mediates estrogeninduced inhibition of vascular smooth muscle cell proliferation. Arterioscler Thromb Vasc Biol 2013;33:1837-1843.

12 Lemay A: The relevance of the Women's Health Initiative results on combined hormone replacement therapy in clinical practice. J Obstet Gynaecol Can 2002;24:711-715.

-13 Rossouw JE, Anderson GL, Prentice RL, LaCroix AZ, Kooperberg C, Stefanick ML, Jackson RD, Beresford SA, Howard BV, Johnson KC, Kotchen JM, Ockene J: Risks and benefits of estrogen plus progestin in healthy postmenopausal women: principal results From the Women's Health Initiative randomized controlled trial. JAMA 2002;288:321-333.

14 Rosano GM, Vitale C, Fini M: Hormone replacement therapy and cardioprotection: what is good and what is bad for the cardiovascular system? Ann N Y Acad Sci 2006;1092:341-348.

15 Simon JA: What's new in hormone replacement therapy: focus on transdermal estradiol and micronized progesterone. Climacteric 2012;15:3-10.

16 Libby P : Inflammation in atherosclerosis. Nature 2002;420:868-874.

17 Stocker R, Keaney JF Jr :Role of oxidative modifications in atherosclerosis. Physiol Rev 2004;84:1381-1478.

-18 Yamaguchi Y, Matsuno S, Kagota S, Haginaka J, Kunitomo M: Fluvastatin reduces modification of lowdensity lipoprotein in hyperlipidemic rabbit loaded with oxidative stress. Eur J Pharmacol 2002;436:97105.

19 Cheng, T.O: Cardiovascular effects of Danshen. Int J Cardiol 2007;121:9-22.

20 Wan AK, Leung SW, Zhu DY, Man RY: Vascular effects of different lipophilic components of "Danshen", a traditional Chinese medicine, in the isolated porcine coronary artery. J Nat Prod 2008;71:1825-1828.

21 Xu S, Little PJ, Lan T, Huang Y, Le K, Wu X, Shen X, Huang H, Cai Y, Tang F, Wang H, Liu P: Tanshinone II-A attenuates and stabilizes atherosclerotic plaques in apolipoprotein-E knockout mice fed a high cholesterol diet. Arch Biochem Biophys 2011;515:72-79.

22 Chen W, Tang F, Xie B, Chen S, Huang H, Liu P: Amelioration of atherosclerosis by tanshinone IIA in hyperlipidemic rabbits through attenuation of oxidative stress. Eur J Pharmacol 2012;674:359-364.

23 Fang ZY, Lin R, Yuan BX, Liu Y, Zhang H:Tanshinone IIA inhibits atherosclerotic plaque formation by downregulating MMP-2 and MMP-9 expression in rabbits fed a high-fat diet. Life Sci 2007;81:1339-1345.

24 Fang ZY, Lin R, Yuan BX, Yang GD, Liu Y, Zhang H: Tanshinone IIA downregulates the CD40 expression and decreases MMP-2 activity on atherosclerosis induced by high fatty diet in rabbit. J Ethnopharmacol 2008;115:217-222.

25 Fan GW, Gao XM, Wang H, Zhu Y, Zhang J, Hu LM, Su YF, Kang LY, Zhang BL: The anti-inflammatory activities of Tanshinone IIA, an active component of TCM, are mediated by estrogen receptor activation and inhibition of iNOS. J Steroid Biochem Mol Biol 2009;113:275-280.

-26 Li X, Du JR, Yu Y, Bai B, Zheng XY: Tanshinone IIA inhibits smooth muscle proliferation and intimal hyperplasia in the rat carotid balloon-injured model through inhibition of MAPK signaling pathway. J Ethnopharmacol 2010;129:273-279.

27 Tang F, Wu X, Wang T, Wang P, Li R, Zhang H, Gao J, Chen S, Bao L, Huang H, Liu P: Tanshinone II A attenuates atherosclerotic calcification in rat model by inhibition of oxidative stress. Vascul Pharmacol 2007;46:427-438.

28 Liang X, He M, Chen T, Wu Y, Tian Y, Zhao Y, Shen Y, Liu Y, Yuan Z:17 $\beta$-estradiol suppresses the macrophage foam cell formation associated with SOCS3. Horm Metab Res 2013;45:423-429. 
29 Hodgin JB, Krege JH, Reddick RL, Korach KS, Smithies O, Maeda N: Estrogen receptor alpha is a major mediator of 17beta-estradiol's atheroprotective effects on lesion size in Apoe-/- mice. J Clin Invest 2001;107:333-340.

-30 Liu Z, Wang J, Huang E, Gao S, Li H, Lu J, Tian K, Little PJ, Shen X, Xu S, Liu P: Tanshinone IIA suppresses cholesterol accumulation in human macrophages: role of heme oxygenase-1. J Lipid Res 2014;55:201-213.

- 31 Victor VM, Apostolova N, Herance R, Hernandez-Mijares A, Rocha M: Oxidative stress and mitochondrial dysfunction in atherosclerosis: mitochondria-targeted antioxidants as potential therapy. Curr Med Chem 2009;16:4654-4667.

- 32 Verreth W, De Keyzer D, Davey PC, Geeraert B, Mertens A, Herregods MC, Smith G, Desjardins F, Balligand JL, Holvoet P: Rosuvastatin restores superoxide dismutase expression and inhibits accumulation of oxidized LDL in the aortic arch of obese dyslipidemic mice. Br J Pharmacol 2007;151:347-355.

33 Tang F, Wu X, Wang T, Wang P, Li R, Zhang H, Gao J, Chen S, Bao L, Huang H, Liu P:Tanshinone II A attenuates atherosclerotic calcification in rat model by inhibition of oxidative stress. Vascul Pharmacol 2007;46:427-438.

34 Chen W, Tang F, Xie B, Chen S, Huang H, Liu P: Amelioration of atherosclerosis by tanshinone IIA in hyperlipidemic rabbits through attenuation of oxidative stress. Eur J Pharmacol 2012;674:359-364.

- 35 Kriszbacher I, Koppan M, Bodis J: Inflammation, atherosclerosis, and coronary artery disease. N Engl J Med 2005;353:429-430.

-36 Steffens S, Mach F: Inflammation and Atherosc- lerosis. Herz 2004;29:741-748.

37 Nabel EG: Biology of the impaired endothelium. Am J Cardiol 1991;68:6C-8C.

- 38 Balanescu S, Calmac L, Constantinescu D, Marinescu M, Onut R, Dorobantu M: Systemic inflammation and early atheroma formation: are they related? Maedica 2010;12,5:292-301.

-39 Tang C, Xue HL, Bai CL, Fu R: Regulation of adhesion molecules expression in TNF- $\alpha$-stimulated brain microvascular endothelial cells by tanshinone IIA: involvement of NF- $\kappa$ B and ROS generation. Phytother Res 2011;25:376-380.

40 Jang SI, Kim HJ, Kim YJ, Jeong SI, You YO: Tanshinone IIA inhibits LPS-induced NF-kappaB activation in RAW 264.7 cells: possible involvement of the NIK-IKK, ERK1/2, p38 and JNK pathways. Eur J Pharmacol 2006;542:1-7.

41 Chang L, Karin M: Mammalian MAP kinase signalling cascades. Nature 2001;410:37-40.

42 Johnson GL, Lapadat R: Mitogen-activated protein kinase pathways mediated by ERK, JNK, and p38 protein kinases. Science 2002;298:1911-1912.

43 Cano E, Mahadevan LC: Parallel signal processing among mammalian MAPKs. Trends Biochem Sci 1995;20:117-122.

44 Han C, Liu J, Liu X, Li M: Angiotensin II induces C-reactive protein expression through ERK1/2 and JNK signaling in human aortic endothelial cells. Atherosclerosis 2010;212:206-242.

45 Lu YG, Fu CH, Yan H: Atorvastatin suppressing endothelial microparticles-inducing upregulation of ICAM-1 in HUVECs by ERK1/2 signal pathway. Chin J Gerontol 2012;3:979-981.

46 Duan JH, Xu HS, Dai SL: Phytoestrogen $\alpha$-Zearalanol inhibition of oxLDL -induced endothelin-1 gene expression and antioxidation. Chin Pharmacol Bull 2006;22:930-934.

47 Ling S, Zhou L, Li H, Dai A, Liu JP, Komesaroff PA, Sudhir K: Effects of 17-estradiol on growth and apoptosis in human vascular endothelial cells: Influence ofmechanical strain and tumor necrosis factor- $\alpha$. Steroids 2006;71:799-808.

48 Guanwei Fan, Yan Zhu, Hao Guo: Direct Vasorelaxation by a Novel Phytoestrogen Tanshinone IIA Is Mediated by Nongenomic Action of Estrogen Receptor Through Endothelial Nitric Oxide Synthase Activation and Calcium Mobilization. J Cardiovasc Pharmacol 2011;3:340-347.

-49 Tang FT, Cao Y, Wang TQ, Wang LJ, Guo J, Zhou XS, Xu SW, Liu WH, Liu PQ, Huang HQ: Tanshinone IIA attenuates atherosclerosis in ApoE(-/-) mice through down-regulation of scavenger receptor expression. Eur J Pharmacol 2011;650:275-284. 